\title{
The bone hormones and their potential effects on glucose and energy metabolism
}

\author{
Daniel Addai, Jacqueline Zarkos, Anna Tolekova \\ Department of Physiology, Faculty of Medicine, Trakia University, Stara Zagora, Bulgaria \\ E-mail:danaddai91@gmail.com
}

\begin{abstract}
The bones form the framework of our body. We know that bones protect our vital organs, regulate calcium and phosphorous homeostasis, and function as a site of erythropoiesis. More recently, however, the identification of bone hormones has allowed us to envision bones as endocrine organs too. Within the last few years, the bone hormones osteocalcin and lipocalin 2 have been implicated with glucose and energy metabolism. We systematically reviewed articles surrounding this subject and found a clear relationship between the osteocalcin levels and glucose tolerance and insulin sensitivity. We also found that many journals have shown the detrimental effects of an absences of lipocalin 2 from adipocytes. As osteocalcin administration to mice showed decreased blood glucose levels and promoted glucose tolerance and insulin sensitivity. Future studies could perhaps explore the use of osteocalcin as a supplement for type 2 diabetes.
\end{abstract}

Key words: osteocalcin, lipocalin 2, glucose, insulin, energy metabolism

Our bones have long been envisioned as the framework of our body. It is a structural appendage that protects our vital organs, regulates calcium and phosphorous homeostasis, and functions as a site of erythropoiesis. In the last decade, the discovery of certain bone hormones has allowed us to observe that bone can also function as an endocrine organ (Guntur and Rosen 2012). Recent studies have shown that at least two bone-derived hormones are implicated in the control of glucose and energy metabolism, namely osteocalcin (OCN) and lipocalin-2 (LCN2) (Mera et al. 2018). Other studies have shown that patients with type 1 and type 2 diabetes have an increased risk of fractures and that hyperglycemia and insulin affects bone metabolism (Bouillon et al. 1995; Janghorbani et al. 2007).

Osteocalcin is a non-collagenous vitamin $\mathrm{K}$-dependent protein that is secreted in the late stage of osteoblasts differentiation (Neve et al. 2013). Accumulating evidence has shown that under carboxylated conditions, OCN stimulates the production and secretion of insulin by the pancreatic $\beta$-cells and adiponectin expression in adipocytes, resulting in improved glucose intolerance (Kanazawa 2015) (Figure 1). Both of these OCN functions are mediated by the G-protein-coupled receptor GPRC6A (Guntur and Rosen 2012; Pi et al. 2016). The GPRC6A receptor belongs to the $\mathrm{C}$ family of GPCRs and is extensively expressed in the body and detects amino acids, steroids, extracellular calcium and osteocalcin (Pi et al. 2011). Correlations between expression of GPRC6A and functional responses to OCN have been observed in both $\beta$-cells and Leydig cells where they stimulate testosterone and 25-hydroxy vitamin D biosynthesis (Pi et al. 2016). OCN has also been shown to stimulate AMPK phosphorylation in pancreatic $\beta$-cells, and thus regulates insulin secretion, cell proliferation, and survival (Pi et al. 2016).

Some studies have shown through molecular and genetic analyses in mice that lipocalin 2 is an osteoblast-enriched secreted protein (Mosialou et al. 2017). Two receptors for LCN2 have been proposed,

Corresponding author: Daniel Addai, Department of Physiology, Faculty of Medicine, Trakia University, str. Armeyska 11, Stara Zagora 6000, Bulgaria; e-mail: danaddai91@gmail.com. 


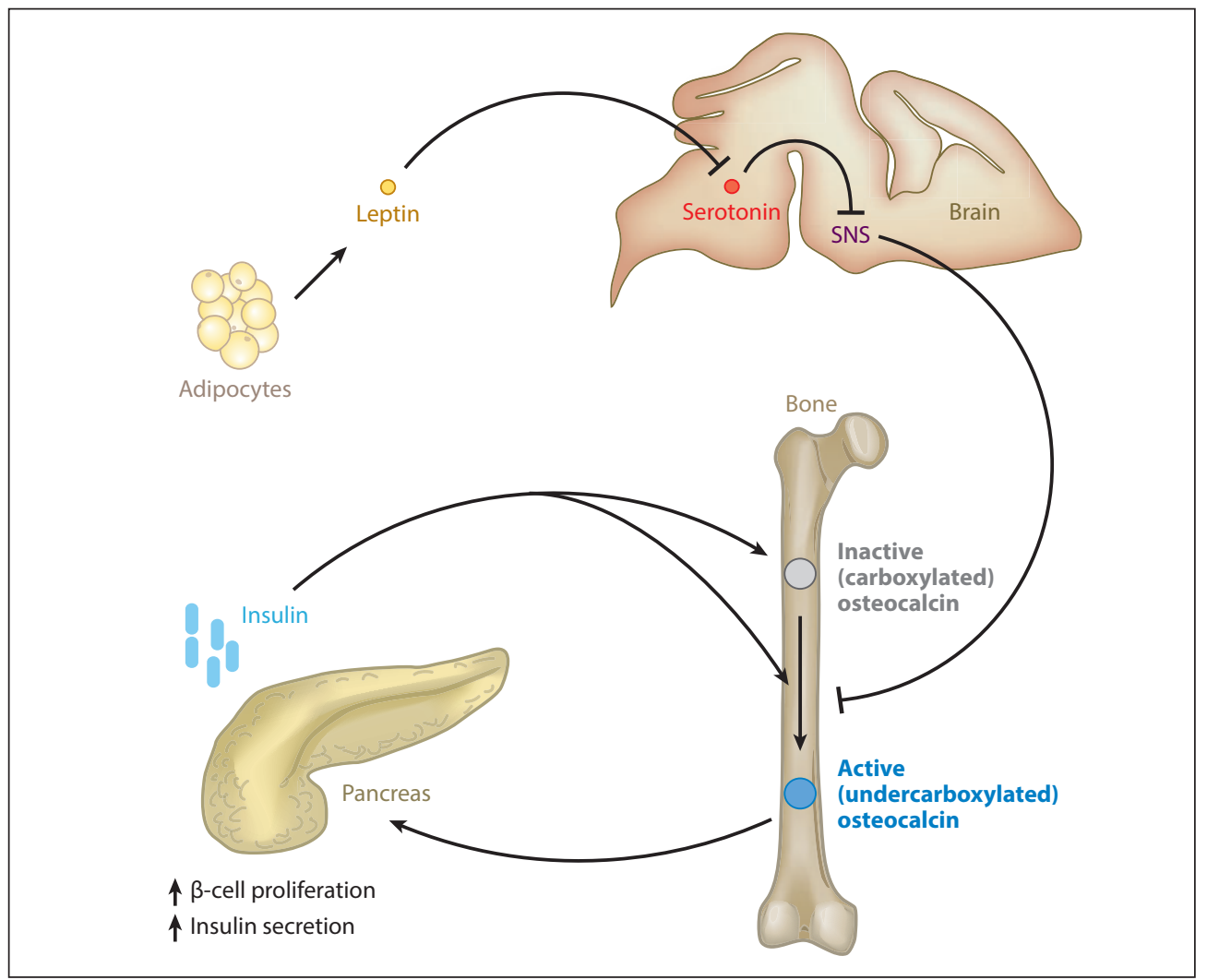

Figure 1. Endocrine regulation of energy metabolism by bone. Bone mediates through osteocalcin that when undercarboxylated - favors $\beta$-cells proliferation and insulin secretion in the pancreas. Insulin favors osteocalcin bioavailability whereas sympathetic tone, regulated by leptin, decreases osteocalcin bioavailability (adapted from Karsenty and Oury 2012).

the transporter protein SLC22A17 (24p3R) and the megalin/glycoprotein GP330 (Hvidberg et al. 2005; Gomez-Chou et al. 2017; Francisco et al. 2018). One of the main functions of LCN2, also known as neutrophil gelatinase-associated lipocalin (NGAL), occurs during an acute infectious process and is associated with its interaction with SLC22A17. Bacteria obtain much of their iron by synthesizing siderophores when inside a host. These siderophages scavenge iron and then deliver it to the bacteria. Upon detection of bacteria, Toll-like receptors of our immune cells stimulate the transcription and translation of LCN2, which sequestrates the iron-laden siderophore and thus inhibits bacterial growth (Flo et al. 2004). SLC22A17 is located in the brain, adrenal gland, endometrium, and many other tissues in the body (Miyamoto et al. 2011; Visscher et al. 2015). Megalin, a giant membrane glycoprotein of $600 \mathrm{kDa}$ that belongs to the low-density lipoprotein receptor (LDLR) protein family is another receptor of LCN2 (Marzolo and Farfan 2011). Megalin is found in the plasma membrane of many absorptive epithelial cells, mainly in the kidney, brain, prostate, placenta and thyroid (Holt et al. 2008).

Experiments in mice have demonstrated that LCN2 maintains glucose homeostasis by promoting insulin secretion and improves glucose tolerance and insulin sensitivity (Guo et al. 2010). Furthermore, osteoblast-derived LCN2 has been shown to inhibit food intake (Palmiter 2017). Mosialou et al. (2017) have described the mechanism of how LCN2 suppresses appetite by crossing the blood-brain barrier, binding to the melanocortin 4 receptor (MC4R) in the hypothalamic paraventricular and ventromedial nuclei neurons and activating an MC4R-dependent anorexigenic pathway.

In mammals, glucose is a major source of energy and is essential for our survival (Guntur and Rosen 2012). Dysfunction in the regulation and utilization of glucose leads to a wide assortment of metabolic syndromes, including Diabetes Mellitus, a vast and growing clinical and public health problem. In 2015, the International Diabetes Federation estimated that 415 million adults had diabetes and that this number 
will increase to 642 million by 2040 (Herman 2017). Furthermore, there have been many studies published documenting the association of diabetes and increased frequency of fractures in such patients (Ivers et al. 2001; de Liefde et al. 2005; Vestergaard 2007). In this study, we review some of the literature surrounding the bone hormones and glucose and energy metabolism.

\section{Osteocalcin}

Ferron et al. (2012) have tested in mice the therapeutic potential of intermittent administration of osteocalcin. They have found that daily injections of osteocalcin ( 3 or $30 \mathrm{ng} / \mathrm{g} /$ day) significantly improved glucose tolerance and insulin sensitivity in mice fed a normal diet. They also felt that this was attributable partly to the observed increase in both $\beta$-cell mass and insulin secretion. Furthermore, mice treated with osteocalcin injections displayed additional mitochondria in their skeletal muscle, increased energy expenditure, and were protected from diet-induced obesity. Finally, hepatic steatosis induced by high fat diet has completely been rescued (Ferron et al. 2012).

One study in 2011, has reported for the first time that undercarboxylated osteocalcin (ucOC) is associated with glucose/fat metabolism in patients with type 2 diabetes. They found that in men, even after multiple regression analysis, ucOC negatively correlated with percent trunk fat, visceral/subcutaneous fat ratio, fasting plasma glucose and $\mathrm{HbA}_{1 \mathrm{c}}$ (independent of age, duration of diabetes, body stature, and renal function) (Kanazawa et al. 2011). Another study has also demonstrated that osteocalcin levels were inversely correlated with the body mass index, fasting glucose and insulin, homeostasis model assessment of insulin resistance, triglycerides, and leptin, and positively correlated with adiponectin, even after adjustment for age and gender (Saleem et al. 2010). Furthermore, in a cross-sectional study, osteocalcin levels were found to be highest in participants with normal glucose tolerance, followed by those with impaired fasting glucose and type 2 diabetes (Liang et al. 2016).

Studies testing the hypothesis that bone cells regulate energy metabolism, found osteocalcin to be a positive regulator of insulin secretion, insulin resistance, and energy expenditure. Astonishingly, insulin signaling in osteoblasts is a positive regulator of osteocalcin production and activation as it can indirectly enhance bone resorption by osteoclasts. On the contrary, leptin is a potent inhibitor of osteocalcin function (Ducy 2011).
Previous studies have shown that members of the class $\mathrm{O}$ of forkhead box transcription factors (FOXO) have important role in the metabolism, cellular proliferation, stress resistance, and apoptosis (Wang et al. 2014). One study has demonstrated that mice lacking Foxo1 only in osteoblasts had increased pancreatic $\beta$ cell proliferation, insulin secretion, and insulin sensitivity. Remarkably, the ability of osteoblast-specific FoxO1 deficiency to affect metabolic homeostasis was due to increased osteocalcin expression and decreased expression of Esp, a gene that encodes a protein that decreases the bioactivity of osteocalcin (Rached et al. 2010).

We have found one study that aimed to investigate the relationship between 25 -hydroxyvitamin $\mathrm{D}$ $[25(\mathrm{OH}) \mathrm{D}]$, osteocalcin, markers of glucose metabolism, and obesity-related parameters. They have demonstrated that $\mathrm{ucOC}$ is related to $25(\mathrm{OH}) \mathrm{D}$ and adiponectin concentrations (Giudici et al. 2017). Neumann et al. (2016) have demonstrated that total OC was lower in males with T1D. Further to this, in T1D patients, the total OC was inversely correlated with BMI and HbAlc, and UC-OC inversely correlated with HbAlc (glycated hemoglobin). Therefore, they concluded that total OC and UC-OC are associated with good glycemic control in T1D (Neumann et al. 2016).

Another study, published by Lee et al. (2007), has shown that mice lacking osteocalcin display decreased $\beta$-cell proliferation, glucose intolerance, and insulin resistance. They have also found that ex vivo, osteocalcin can stimulate Cyclin D1 and insulin expression in $\beta$-cells and adiponectin in adipocytes and that in vivo osteocalcin can improve the glucose tolerance (Lee et al. 2007).

In an outstanding study, an extract containing both Gla- and GluOC from boiled pork bone was prepared and subsequently tested whether the extract might beneficially influence the improving metabolic parameters in obese mice. They have found that daily oral administration of the extract for four weeks decreased blood glucose levels and promoted glucose tolerance as well as insulin sensitivity (Mizokami et al. 2016).

Wei and Karsenty (2015) have generated mice lacking osteoblast testis specific protein tyrosine phosphatase (OST-PTP), which is encoded by a gene termed Esp. They have found that Esp-/-mice exhibited the same phenotype made of hypoglycemia, hyperinsulinemia, and increased glucose utilization by peripheral tissues. What is more, mice lacking Esp in all cells or in osteoblasts had only significantly less visceral fat (Wei and Karsenty 2015). 


\section{Lipocalin 2}

Mosialou et al. (2017) have identified in mice lipocalin 2 (LCN2) as an osteoblast enriched secreted protein. In addition, their studies have demonstrated that osteoblast derived LCN2 maintains glucose homeostasis by inducing insulin secretion and improves glucose tolerance and insulin sensitivity. Furthermore, osteoblast-derived LCN2 inhibits food intake. They have found that LCN2 crosses the bloodbrain barrier, binds to the melanocortin 4 receptor (MC4R) in the hypothalamic paraventricular and ventromedial nuclei neurons and activates an MC4Rdependent anorexigenic pathway (Mosialou et al. 2017).

Systemic insulin sensitivity, adaptive thermogenesis, and serum metabolic and lipid profile were assessed in LCN2-deficient mice fed a high-fat diet (HFD) or regular chow diet in one study. In mice, the in vivo disruption of LCN2 resulted in significantly potentiated diet-induced obesity, dyslipidemia, fatty liver disease, and insulin resistance. They have also found that gene expression patterns in white and brown adipose tissue, liver, and muscle indicate that $\mathrm{LCN}^{-/-}$mice have increased hepatic gluconeogenesis, decreased mitochondrial oxidative capacity, impaired lipid metabolism, and increased inflammatory state under the HFD condition (Francisco et al. 2018).

In another study, fatty liver was triggered in rats fed either with liquid Lieber-DeCarli (LDC) or LDC $+70 \%$ cal fructose (L-HFr) diet for 4 or 8 weeks. They have found that fructose diet up-regulates hepatic LCN2 expression, which correlates with the increased indicators of oxidative stress and mitochondrial dysfunction. Thus, they concluded that LCN2 may be involved in liver protection (Alwahsh et al. 2014). Another study has shown that expression of LCN2 is elevated by agents that promote insulin resistance and is reduced by thiazolidinediones. LCN2 serum levels are elevated in multiple rodent models of obesity and forced reduction of LCN2 in 3T3-L1 adipocytes improves insulin action. They have also found that exogenous LCN2 promotes insulin resistance in cultured hepatocytes (Yan et al. 2007). Lambertz et al. (2017) have reported that fructose-induced steatosis and liver damage was more prominent in female than in male mice, but that intriguingly, the most severe hepatic damage occurred in the female mice lacking LCN2.

\section{Conclusions}

Many studies, have shown a clear relationship between the osteocalcin levels and glucose tolerance and insulin sensitivity. However, the discovery of lipocalin 2, as an osteoblast enriched, secreted protein is relatively new and as a consequence, there is a need for further studies on the topic. Nevertheless, we have found many journals indicating the detrimental effects of an absence of lipocalin 2 from adipocytes, namely increased hepatic gluconeogenesis, decreased mitochondrial oxidative capacity, impaired lipid metabolism, and increased inflammatory state. One study has also intriguingly reported that the most severe hepatic damage occurred in mice lacking LCN2. All this suggests that with further studies, associations between diet-induced obesity, dyslipidemia, fatty liver disease might be made with bone derived LCN2.

One study has demonstrated that the administration of osteocalcin in mice decreased the blood glucose levels and promoted glucose tolerance as well as insulin sensitivity. Perhaps in the future one think hard about the use of osteocalcin as a supplement for patients with type 2 diabetes, specifically on the required daily dosage to see such a protective effect.

\section{References}

Alwahsh SM, Xu M, Seyhan HA, Ahmad S, Mihm S, Ramadori G, Schultze FC. Diet high in fructose leads to an overexpression of lipocalin-2 in rat fatty liver. World J Gastroenterol 20, 1807-1821, 2014.

Bouillon R, Bex M, Van Herck E, Laureys J, Dooms L, Lesaffre E, Ravussin E. Influence of age, sex, and insulin on osteoblast function: osteoblast dysfunction in diabetes mellitus. J Clin Endocrinol Metab 80, 1194-1202, 1995.

de Liefde II, van der Klift M, de Laet CE, van Daele PL, Hofman A, Pols HA. Bone mineral density and fracture risk in type-2 diabetes mellitus: the Rotterdam Study. Osteoporos Int 16, 1713-1720, 2005.

Ducy P. The role of osteocalcin in the endocrine cross-talk between bone remodelling and energy metabolism. Diabetologia 54, 1291-1297, 2011.

Ferron M, McKee MD, Levine RL, Ducy P, Karsenty G. Intermittent injections of osteocalcin improve glucose metabolism and prevent type 2 diabetes in mice. Bone 50, 568-575, 2012.

Flo TH, Smith KD, Sato S, Rodriguez DJ, Holmes MA, Strong RK, Akira S, Aderem A. Lipocalin 2 mediates an innate immune response to bacterial infection by sequestrating iron. Nature 432, 917-921, 2004. 
Francisco V, Pino J, Gonzalez-Gay MA, Mera A, Lago F, Gomez R, Mobasheri A, Gualillo O. Adipokines and inflammation: is it a question of weight? Br J Pharmacol 175, 1569-1579, 2018.

Giudici KV, Fisberg RM, Marchioni DML, Peters BSE, Martini LA. Crosstalk between bone and fat tissue: associations between vitamin $\mathrm{D}$, osteocalcin, adipokines, and markers of glucose metabolism among adolescents. J Am Coll Nutr 36, 273-280, 2017.

Gomez-Chou SB, Swidnicka-Siergiejko AK, Badi N, Chavez-Tomar M, Lesinski GB, Bekaii-Saab T, Farren MR, Mace TA, Schmidt C, Liu Y, Deng D, Hwang RF, Zhou L, Moore T, Chatterjee D, Wang H, Leng X, Arlinghaus RB, Logsdon CD, Cruz-Monserrate Z. Lipocalin-2 promotes pancreatic ductal adenocarcinoma by regulating inflammation in the tumor microenvironment. Cancer Res 77, 2647-2660, 2017.

Guntur AR, Rosen CJ. Bone as an endocrine organ. Endocr Pract 18, 758-762, 2012.

Guo H, Jin D, Zhang Y, Wright W, Bazuine M, Brockman D, Bernlohr D, Chen, X. Lipocalin-2 deficiency impairs thermogenesis and potentiates diet-induced insulin resistance in mice. Diabetes 59, 1376-1385, 2010.

Herman W. The global burden of diabetes: An overview. In: Diabetes mellitus in developing countries and underserved communities (Ed. S. Dagogo-Jack), Springer International Publishing, Switzerland, pp. 1-5, 2017.

Holt SK, Karyadi DM, Kwon EM, Stanford JL, Nelson PS, Ostrander EA. Association of Megalin genetic polymorphisms with prostate cancer risk and prognosis. Clin Cancer Res 14, 3823-3831, 2008.

Hvidberg V, Jacobsen C, Strong RK, Cowland JB, Moestrup SK, Borregaard N. The endocytic receptor megalin binds the iron transporting neutrophil-gelatinase-associated lipocalin with high affinity and mediates its cellular uptake. FEBS Lett 579, 773-777, 2005.

Ivers RQ, Cumming RG, Mitchell P, Peduto AJ; Blue Mountains Eye Study. Diabetes and risk of fracture. Diabetes Care 24, 1198-1203, 2001.

Janghorbani M, Van Dam RM, Willett WC, Hu FB. Systematic review of type 1 and type 2 diabetes mellitus and risk of fracture. Am J Epidemiol 166, 495-505, 2007.

Kanazawa I, Yamaguchi T, Yamauchi M, Yamamoto M, Kurioka S, Yano S, Sugimoto T. Serum undercarboxylated osteocalcin was inversely associated with plasma glucose level and fat mass in type 2 diabetes mellitus. Osteoporos Int 22, 187-194, 2011.

Kanazawa I. Osteocalcin as a hormone regulating glucose metabolism. World J Diabetes 6, 1345-1354, 2015.

Karsenty G, Oury F, Biology without walls: the novel endocrinology of bone. Annu Rev Physiol 74, 87-105, 2012.

Lambertz J, Berger T, Mak TW, van Helden J, Weiskirchen R. Lipocalin-2 in fructose-induced fatty liver disease. Front Physiol 8, 964, 2017.

Lee NK, Sowa H, Hinoi E, Ferron M, Ahn JD, Confavreux C, Dacquin R, Mee PJ, McKee MD, Jung DY, Zhang Z, Kim JK, Mauvais-Jarvis F, Ducy P, Karsenty G. Endocrine regulation of energy metabolism by the skeleton. Cell 130, 456-469, 2007.

Liang Y, Tan A, Liang D, Yang X, Liao M, Gao Y, Jiang Y, Yao Z, Lin X, Lu Z, Wu C, Zhang S, Hu Y, Qin X, Mo Z, Li $\mathrm{H}$, Zhang $\mathrm{H}$. Low osteocalcin level is a risk factor for impaired glucose metabolism in a Chinese male population. J Diabetes Investig 7, 522-528, 2016.

Marzolo PM, Farfan P. New insights into the roles of megalin/LRP2 and the regulation of its functional expression. Biol Res 44, 89-105, 2011.

Mera P, Ferron M, Mosialou I. Regulation of energy metabolism by bone-derived hormones. Cold Spring Harb Perspect Med 8, a031666, 2018.

Mizokami A, Wang D, Tanaka M, Gao J, Takeuchi H, Matsui T, Hirata M. An extract from pork bones containing osteocalcin improves glucose metabolism in mice by oral administration. Biosci Biotechnol Biochem 80, 2176-2183, 2016.

Miyamoto T, Asaka R, Suzuki A, Takatsu A, Kashima H, Shiozawa T. Immunohistochemical detection of a specific receptor for lipocalin2 (solute carrier family 22 member 17, SLC22A17) and its prognostic significance in endometrial carcinoma. Exp Mol Pathol 91, 563-568, 2011.

Mosialou I, Shikhel S, Liu J, Maurizi A, Luo N, He Z, Huang Y, Zong H, Friedman R, Barasch J, Lanzano P, Deng L, Leibel R, Rubin M, Nickolas T, Chung W, Zeltser L, Williams K, Pessin J, Kousteni S. MC4R-dependent suppression of appetite by bone-derived lipocalin 2. Nature 543, 385-390, 2017.

Neumann T, Lodes S, Kastner B, Franke S, Kiehntopf M, Lehmann T, Muller UA, Wolf G, Samann A. Osteocalcin, adipokines and their associations with glucose metabolism in type 1 diabetes. Bone 82, 50-55, 2016.

Neve A, Corrado A, Cantatore FP. Osteocalcin: skeletal and extra-skeletal effects. J Cell Physiol 228, 1149-1153, 2013.

Palmiter RD. Physiology: Bone-derived hormone suppresses appetite. Nature 543, 320-322, 2017.

Pi M, Wu Y, Quarles LD. GPRC6A mediates responses to osteocalcin in $\beta$-cells in vitro and pancreas in vivo. J Bone Miner Res 26, 1680-1683, 2011. 
Pi M, Kapoor K, Ye R, Nishimoto SK, Smith JC, Baudry J, Quarles LD. Evidence for osteocalcin binding and activation of GPRC6A in $\beta$-cells. Endocrinology 157, 1866-1880, 2016.

Rached MT, Kode A, Silva BC, Jung DY, Gray S, Ong H, Paik JH, DePinho RA, Kim JK, Karsenty G, Kousteni S. FoxO1 expression in osteoblasts regulates glucose homeostasis through regulation of osteocalcin in mice. J Clin Invest 120, 357-368, 2010.

Saleem U, Mosley TH Jr, Kullo IJ. Serum osteocalcin is associated with measures of insulin resistance, adipokine levels, and the presence of metabolic syndrome. Arterioscler Thromb Vasc Biol 30, 1474-1478, 2010.

Vestergaard P. Discrepancies in bone mineral density and fracture risk in patients with type 1 and type 2 diabetes--a meta-analysis. Osteoporos Int 18, 427-444, 2007.

Visscher V, Rassekh SR, Sandor GS, Caron HN, van Dalen EC, Kremer LC, van der Pal HJ, Rogers PC, Rieder MJ, Carleton BC, Hayden MR, Ross CJ; CPNDS consortium. Genetic variants in SLC22A17 and SLC22A7 are associated with anthracycline-induced cardiotoxicity in children. Pharmacogenomics 16, 1065-1076, 2015.

Wang Y, Zhou Y, Graves DT. FOXO transcription factors: their clinical significance and regulation. Biomed Res Int 2014, 925350, 2014.

Wei J, Karsenty G. An overview of the metabolic functions of osteocalcin. Rev Endocr Metab Disord 16, 93-98, 2015.

Yan QW, Yang Q, Mody N, Graham TE, Hsu CH, Xu Z, Houstis NE, Kahn BB, Rosen ED. The adipokine lipocalin 2 is regulated by obesity and promotes insulin resistance. Diabetes 56, 2533-2540, 2007. 